\title{
Localization and morphometric evaluation of Supraorbital and Infraorbital foramen in Dravidian Population of Southern India: A paleoantropological study on dry skulls.
}

\author{
Dr. Sivavadivel Swaminathan ${ }^{1}$, Dr. Navaneetha Cugati ${ }^{2}$, Dr. Senthil Kumar ${ }^{3}$ \\ 1 (Lecturer in Anatomy, Faculty of Medicine, AIMST University, , Malaysia) \\ 2 ( Lecturer in Pediatric Dentistry, Faculty of Dentistry, AIMST University, Malaysia) \\ 3 (Professorin Anatomy, Sri Ramachandra University, India)
}

\begin{abstract}
Purpose:To determine the morphology and morphometric distance of supraorbital foramen/ notch(SOF/N) and infrorbital foramen(IOF) from different important anatomical landmark. Method:Sixty-five dry adult Dravidian skulls(130 sides) of Southern India were investigated to analyze the frequency of occurrence of SOF/N and shape of IOF. Fourty skulls (80 sides) were assessed to measure the width and positioning of SOF/N and IOF. Results: Mean width of SON/F and IOF was $2.86 \mathrm{~mm}$ and 3.85 respectively. The average distance of SOF/N was $25.9 \mathrm{~mm}$ lateral to nasion, $28.5 \mathrm{~mm}$ medial to temporal crest of the frontal bone, $0.92 \mathrm{~mm}$ superior to supraorbital rim. The distance between right and left SOF/N was 49.6mm.The IOF was at an average of $44.08 \mathrm{~mm}$ lateral to nasion, $41.36 \mathrm{~mm}$ lateral to maxillary midline, $6.82 \mathrm{~mm}$ below infraorbital rim, $2.8 \mathrm{~mm}$ medial to zygomaticomaxillary suture, $34.8 \mathrm{~mm}$ lateral to anterior nasal spine and $27.45 \mathrm{~mm}$ from the alveolar crest. SOF/N was located at an average of 8.3 degree from IOF. IOF was in line with maxillary second premolar and the direction of opening was pointed inferomedially. The mean value of all the measurements was made between the right and left sides using independent t-test showed no statistical significance (where p>0.05).Conclusion: These morphometric measurements facilitate the professionals to locate the neurovascular bundles passing through the foramen and also assist in non-invasive as well as invasive surgical procedures.
\end{abstract}

Key-Words: Anatomical Variation; Dravidian, Foramen, Location, Skull .

\section{Introduction}

Variation in the racial and regional population demands a thorough understanding of morphometric evaluation of foramen in the maxillofacial region[1,2,3]. Neurovascular bundles exiting from Supraorbital foramen(SOF)/ Supraorbital Notch (SON), on the medial aspect of supraorbital margin of the frontal bone and Infraorbital foramen (IOF), below the infraorbital margin in the maxillary bone nurture majority of the neuromuscular structures of the maxilla-facial region. Their location from anatomical reference points facilitate surgical, diagnostic, therapeutic, local anesthetic and other invasive procedures, without causing any injury to the surrounding vital structures[4,5,6]. Despite its significance, little is known about the morphometric details of supraorbital and infraorbital foramen in Dravidian population of Southern India. Hence this study was carried out to elucidate the number, shape, position and orientation of supraorbital and infraorbital foramen in relation to the anatomical landmarks in dry skulls of Dravidian population.

\section{Material And Methods}

A total of 65 adult dry Dravidian skulls were collected from the Department of Anatomy, Faculty of Medicine, Sri Ramachandra Medical College and Research Institute, Chennai, Tamilnadu, India for study purpose. Approval for the research protocol was obtained from the Institution Review Board of Sri Ramachandra University, Chennai, India and the study followed the Declaration of Helsinki on medical protocol and ethics . Of the total, only 40 dry skulls were suitable for this investigation. Therefore Sixty-five dry skulls (130 sides) were investigated to analyze the frequency of occurrence of SOF/N and shape of IOF. Forty skulls ( 80 sides) were assessed to measure the width and positioning of SOF/N and IOF.

The age and gender for the dry skulls were not determined in this study. Both the sides of each skull were assessed for the shape, size, position, orientation and morphometric location of SON/F and IOF from different anatomical landmarks. The data were recorded separately by two examiners, using vernier caliper and flexible ruler, with least error being $0.01 \mathrm{~mm}$ under direct visual examination. The angle was measured using geometrical protractor and the direction of foramen opening was identified by inserting 25 gauge hypodermic needle into the foramen.

The frequency of occurrence of supraorbital foramen, notch, notch with foramen and multiple foramina and its relative position from the nasion in nasal midline, temporal crest, its distance to supraorbital rim, 
distance between the right and the left SON/F, width of the foramen and the difference angle between SOF/ SON to infraorbital foramen were recorded. The shapes of IOF were described as oval, round or semilunar and the direction of its opening was noted. The morphometric location of infraorbital foramen was measured from its distance to the center of Zygomatico-Maxillary(Zy-Max), suture infraorbital rim, nasion, anterior nasal spine, maxillary midline, maxillary alveolar crest ; distance between right and left foramina; its location with the long axis of maxillary teeth; width of infraorbital foramen were calibrated.

All the measurements were repeated twice by each examiner and the mean was taken for future analysis. The distances were measured as mean, $S D$, range and independent ' $t$ ' test was performed to determine the statistical significance $(\mathrm{p}<0.05)$ for the right and left sides.

\section{Results}

A total 65 dry skulls (130 sides) were investigated to find the frequency of occurrence of supraorbital foramen or notch. Among them 74 sides (52.3\%) had notch, 41 sides (31.2\%) had foramen. 8 sides had both notch and foramen, 6 sides found to have double foramen, one side had triple foramen, summing to 15 sides $(11.5 \%)$ that had accessory foramen, as shown in Graph 1. Of the total only 40 skulls (80 sides) were eligible for analyzing the position of SOF/N. All the skulls studied displayed supraorbital foramen on either side. Its position from different anatomical reference points are summarized in Table 1.Similarly, the mean distance of $\mathrm{SOF} / \mathrm{N}$ from different anatomical landmarks is shown in Table 2.

The frequently encountered shape of IOF was oval with a total of $73.07 \%$; round shaped foramen was in $18.45 \%$, semilunar shaped was in $8 \%$ of the examined dry skulls and is shown in Graph 2 . The direction of opening of Infraorbital foramen was Inferomedial in all the 80 sides of 40 skulls. The positioning of the Infraorbital Foramen from important anatomical reference points are summarized in Table 3. Similarly, the mean distance of IOF/ $\mathrm{N}$ from different anatomical landmarks is shown in Table 4.

\section{DISCUSSION}

The current study provides valuable information on the detailed morphometric measurements of SOF/N and $\mathrm{IOF} / \mathrm{N}$ from important anatomical landmarks, enabling effective nerve block and preventing neurovascular bundle injury.

\subsection{Supraorbital Notch and Foramen:}

The supraorbital nerve is clinically important in that it causes neuralgia especially, 'swimmers neuralgia'. Apinhasmit et al. in 2006 observed 50\% of the study samples had bilateral SON, 17\% had bilateral SOF and $33 \%$ had a notch on one side and a foramen on the other side, multiple supraorbital foramen was found in $8 \%$ in Thai population[7]. Webster et al. in 1986 reported the distribution of $49.07 \%$ of bilateral supraorbital notches, $25.93 \%$ of bilateral supraorbital foramen and $25 \%$ of notch on one side and foramen on contralateral side[8] Keskil et al 2003, Chung in 1995 among Koreans, Brain Cutright et al 2003 in black reported higher incidence of supraorbital notch than foramen for about $92.5 \%$, similarly the present study reported comparatively a higher incidence of SON in 74 sides (52.3\%) than SOF in 41 sides $(31.2 \%)$ and lesser incidence of both notch with foramen in 8 sides $(10.76 \%)$, than the previous studies in south Indian population $[1,9,10]$.

Tulika Gupta et al 2008, observed accessory supraorbital foramen present in 14\% of skull, Sithiporn Agthong et al 2005 observed in $3.6 \%$ cases and Saylam et al 2003 in $2 \%$ cases in Turkish Crania[6,11,12]. But in the present study accessory supraorbital foramen was found in 15 sides $(11.5 \%)$, which is more than previous studies. Saylam et al 2003 stated that the frequency of absence of SOF/N was in $5.5 \%$ on right and $10 \%$ on left side of skull[12]. Beer et al 1998 showed 3\% absence in European skull [13]. But in this study there was no absence of notch / foramen.

The position of $\mathrm{SOF} / \mathrm{N}$, varied in different population. Its distance was $25 \mathrm{~mm}$ lateral to the midline according to observation by Tulika Gupta in 2008; Aziz et al 2000 found the distance to be 26.4mm; Brain Cutright et al. as $25 \mathrm{~mm}$ and Wandee Apinhasmit et al as $25.14 \mathrm{~mm}$ in Thais, but in the present study it was about $25.9 \mathrm{~mm}$ lateral to the midline. In Thais, it was observed that the distance of SOF was $30 \mathrm{~mm}$ medial to the temporal crest and in Blacks $26 \mathrm{~mm}$ medial to the temporal crest[1,3]. But in the present study it was observed about $28.5 \mathrm{~mm}$ medial to the temporal crest of the frontal bone. Chung 1995 observed in Korean skull SOF, IOF and MF are aligned in same sagittal plane in $38.1 \%$ and SOF/ SON were located at an average angle of 5.8 degree from the IOF[10]. In the present study SOF, IOF, MF is aligned in same sagittal plane in $8.25 \%$ and $\mathrm{SOF} / \mathrm{N}$ were located at an average angle of 8.3 degree from the IOF. In this study the average width of SOF as $2.8 \mathrm{~mm}$, similar with Apinhasmit's observation in Thais $(2.81 \mathrm{~mm})[3]$, whereas in Koreans it was $4.7 \mathrm{~mm}$ wide[10]

\subsection{Infraorbital foramen:}

Previous studies by Aziz et al. observed accessory IOF in 15\% of cadavers. Accessory IOF in 3.8\% of Thai adult skulls[3]. Saylam observed accessory canals in $3.6 \%$ on right crania and $4.5 \%$ in left crania[12]. 
Present study encountered accessory canals in $2.5 \%$ of the cases. Gupta $\mathrm{T}$ et al stated that IOF was $7 \mathrm{~mm}$ inferior to infraorbital rim[11]. Chung et al found, it was $8.6 \mathrm{~mm}$ for Korean skull[10], Aziz et al it was 8.5 $\pm 2.2 \mathrm{~mm}$ [14]. Agthong $\mathrm{S}$ stated as $7.8 \pm 0.2 \mathrm{~mm}$ in Asian population[6]. Cutright B as $6.4 \mathrm{~mm}[1]$. In the present study it was $6.82 \mathrm{~mm}$ from infraorbital rim. Among Thai skulls 50\% were oval, 29\% semilunar, 21\% circular foramen[3]. Present study found $73.07 \%$ oval, $18.45 \%$ round and $8 \%$ semilunar. L Gupta et al stated that IOF was in vertical line with second premolar[11], Aziz et all with first premolar[14], Apinhasmit et al in second premolar among Thai skulls[3]. Murphy et al observed in aborigines IOF was in line with second premolar tooth ${ }^{15}$. But in the present study, IOF was in line with upper second premolar in 65 sides $(81.25 \%)$, between maxillary second premolar and first molar in 11 sides $(13.75 \%)$ and in line with first molar in 4 sides $(5 \%)$. Chung et al observed the average width was $4.8 \mathrm{~mm}$ [10] among Koreans and Apinhasmit 3.35mm among Thais[3]. In this present study it was $3.8 \mathrm{~mm}$.

The distance of IOF was $28.5 \mathrm{~mm}$ lateral to nasal midline ${ }^{11}$ as stated by Gupta; Aziz et al $27.7 \pm 4.3 \mathrm{~mm}$ in males and $26.2 \pm 3.2 \mathrm{~mm}$ in females[14], Cutright et al $25 \mathrm{~mm}$ lateral to midline[1]. But the present study IOF was very much lateral by $44.07 \mathrm{~mm}$. Agthong stated IOF to ANS was $34.1 \pm 0.2 \mathrm{~mm}$ [6] But the present study IOF was $34.8 \mathrm{~mm}$ lateral to the ANS. Cutright observed that IOF was $3 \mathrm{~mm}$ medial to the Zy-max suture[1], Apinhasmit stated $2.15 \mathrm{~mm}$ medial to ZY-MZ suture[3]. Blanton and Jeske et al found the IOF 5mm below Zymax suture[16]. The present study it was $2.8 \mathrm{~mm}$ from Zy-Max suture.

Among Blacks, Cutright observed IOF was $27 \mathrm{~mm}$ lateral to the mid maxillary line[1]. In Thais it was $28.43 \mathrm{~mm}$ lateral[3]. But the present study it was $41.36 \mathrm{~mm}$ from the midline, which is higher than other population. Brando HF et al observed the distance from IOF to alveolar crest was $33.4 \mathrm{~mm}$. But the present study IOF was $27.45 \mathrm{~mm}$ from the alveolar crest, which is far less compare to this observation[17].

\section{FIGURES AND TABLES}

FIGURE 1: The measurement of SON/F and IOF in relation to important anatomical landmarks

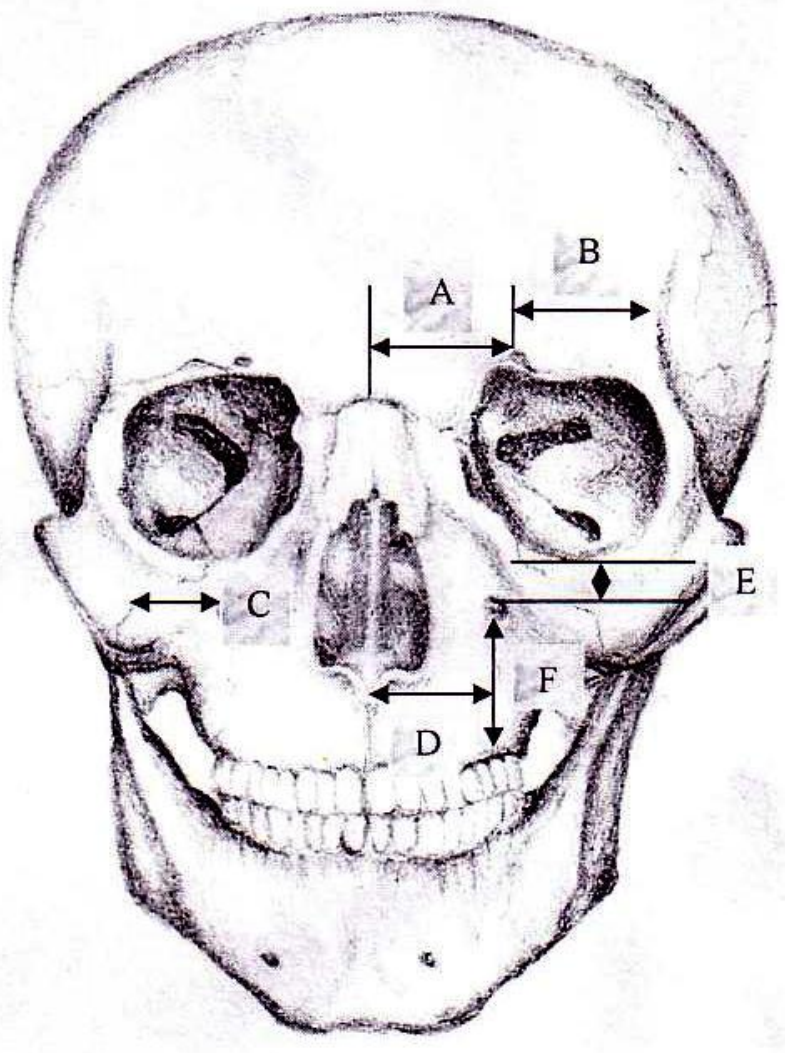

A,B- distance from SON/F to nasal midline and temporal crest of the frontal bone, respectively; C,D,E,F- distance between IOF to Zygomaticomaxillary suture, maxillary midline, infraorbital rim, maxillary alveolar crest respectively. 
GRAPH 1 :Frequency of Occurrence of Supraorbital Notch/ Foramen

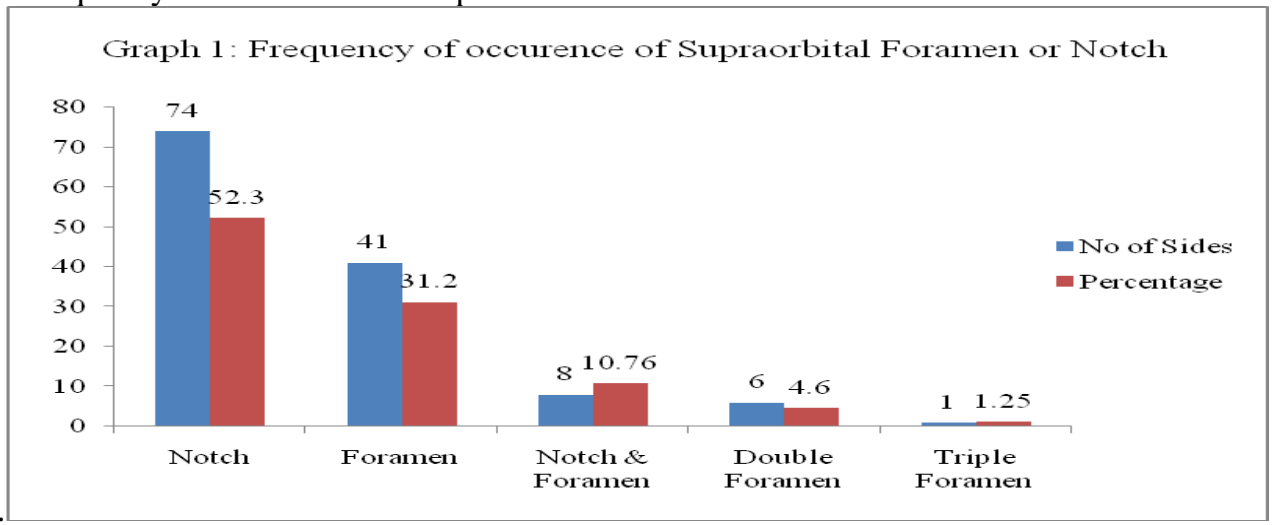

GRAPH 2 : Shape of Infraorbital Notch/ Foramen.

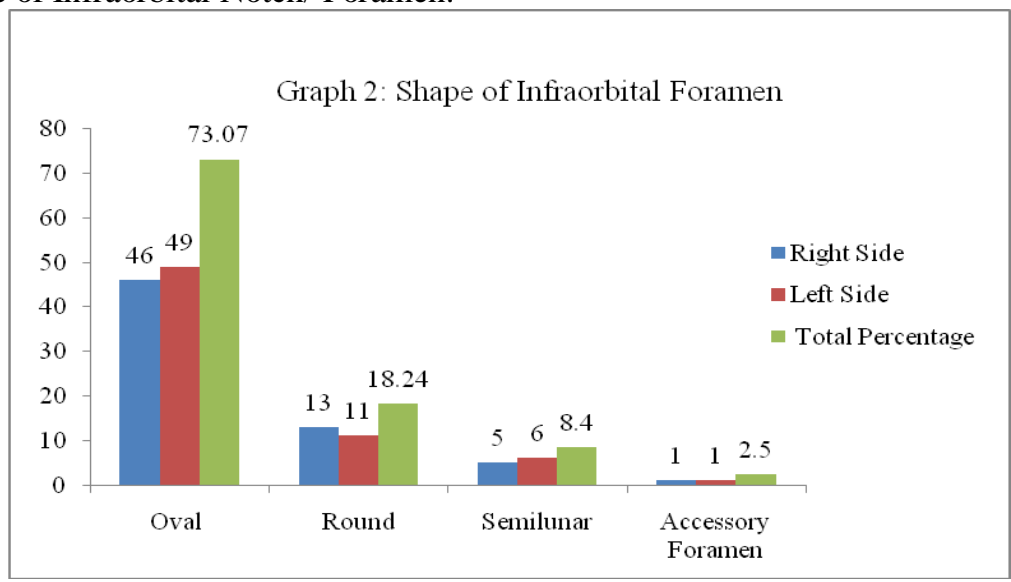

TABLE 1: The morphometric distance of $S O F / N$ on right and left side of the skull from different anatomical reference point.

\begin{tabular}{|c|c|c|c|c|c|c|c|c|c|c|c|c|c|}
\hline \multirow[t]{2}{*}{$\begin{array}{l}\mathbf{N} \\
\text { o. }\end{array}$} & \multicolumn{2}{|c|}{ Nasion } & \multicolumn{2}{|c|}{$\begin{array}{l}\text { Temporal } \\
\text { Crest }\end{array}$} & \multicolumn{2}{|c|}{$\begin{array}{l}\text { Supraorbital } \\
\text { Rim }\end{array}$} & \multirow[t]{2}{*}{ No. } & \multicolumn{2}{|c|}{ Nasion } & \multicolumn{2}{|c|}{$\begin{array}{l}\text { Temporal } \\
\text { Crest }\end{array}$} & \multicolumn{2}{|c|}{$\begin{array}{l}\text { Supraorbital } \\
\text { Rim }\end{array}$} \\
\hline & $\begin{array}{l}\text { Left } \\
\text { Side }\end{array}$ & $\begin{array}{l}\text { Right } \\
\text { Side }\end{array}$ & $\begin{array}{l}\text { Left } \\
\text { Side }\end{array}$ & $\begin{array}{l}\text { Right } \\
\text { Side }\end{array}$ & $\begin{array}{l}\text { Left } \\
\text { Side }\end{array}$ & $\begin{array}{l}\text { Right } \\
\text { Side }\end{array}$ & & $\begin{array}{l}\text { Left } \\
\text { Side }\end{array}$ & $\begin{array}{l}\text { Right } \\
\text { Side }\end{array}$ & $\begin{array}{l}\text { Left } \\
\text { Side }\end{array}$ & $\begin{array}{l}\text { Right } \\
\text { Side }\end{array}$ & $\begin{array}{l}\text { Left } \\
\text { Side }\end{array}$ & $\begin{array}{l}\text { Rig } \\
\text { ht } \\
\text { Side }\end{array}$ \\
\hline 1 & 29 & 29 & 26 & 27 & 1 & 1 & 21 & 21 & 23 & 29 & 27 & 0.7 & 0 \\
\hline 2 & 27 & 27 & 26 & 25 & 1.8 & 2.1 & 22 & 22 & 23 & 27 & 29 & 0 & 0 \\
\hline 3 & 24 & 24 & 30 & 31 & 0 & 0 & 23 & 26 & 26 & 31 & 30 & 2 & 2.2 \\
\hline 4 & 29 & 27 & 25 & 24 & 0 & 1.6 & 24 & 21 & 22 & 26 & 27 & 0 & 0 \\
\hline 5 & 21 & 22 & 34 & 33 & 2.1 & 2.5 & 25 & 27 & 25 & 26 & 29 & 5 & 3.5 \\
\hline 6 & 27 & 27 & 29 & 31 & 0 & 0 & 26 & 24 & 22 & 27 & 35 & 3 & 1.8 \\
\hline 7 & 29 & 30 & 28 & 27 & 1 & 0 & 27 & 37 & 28 & 27 & 29 & 1.8 & 0 \\
\hline 8 & 23 & 24 & 31 & 31 & 0 & 0 & 28 & 26 & 23 & 22 & 27 & 2.8 & 0 \\
\hline 9 & 30 & 27 & 32 & 29 & 0 & 0 & 29 & 27 & 26 & 35 & 24 & 1.8 & 2.8 \\
\hline 10 & 31 & 25 & 26 & 31 & 3.5 & 2 & 30 & 30 & 26 & 25 & 39 & 3.1 & 0 \\
\hline 11 & 29 & 28 & 28 & 27 & 0 & 0 & 31 & 25 & 26 & 34 & 26 & 0 & 2.1 \\
\hline 12 & 24 & 25 & 33 & 32 & 0 & 0 & 32 & 25 & 28 & 36 & 30 & 0 & 0 \\
\hline 13 & 27 & 27 & 39 & 28 & 0 & 0 & 33 & 25 & 27 & 31 & 31 & 1.8 & 0 \\
\hline 14 & 24 & 24 & 25 & 25 & 0 & 0 & 34 & 28 & 22 & 30 & 27 & 2 & 0 \\
\hline 15 & 26 & 28 & 29 & 30 & 0 & 0 & 35 & 22 & 25 & 33 & 29 & 0 & 0 \\
\hline 16 & 25 & 26 & 30 & 31 & 1.8 & 2.5 & 36 & 27 & 24 & 31 & 27 & 0 & 3 \\
\hline
\end{tabular}




\begin{tabular}{|c|c|c|c|c|c|c|c|c|c|c|c|c|c|}
\hline 17 & 23 & 24 & 24 & 25 & 0 & 0 & 37 & 28 & 27 & 32 & 30 & 2.5 & 0 \\
\hline 18 & 29 & 31 & 23 & 21 & 0 & 0 & 38 & 26 & 30 & 30 & 27 & 0 & 0 \\
\hline 19 & 28 & 24 & 29 & 32 & 0 & 2 & 39 & 25 & 26 & 27 & 22 & 2.1 & 2.8 \\
\hline 20 & 28 & 23 & 28 & 31 & 0 & 0 & 40 & 26 & 23 & 31 & 27 & 2.3 & 0 \\
\hline & & & & & & & $\begin{array}{l}\text { Mea } \\
\text { n }\end{array}$ & 26.27 & 25.68 & 28.87 & 28.32 & 1.05 & 0.79 \\
\hline
\end{tabular}

TABLE 2:The mean morphometric distance of SOF/N in dry skull from different anatomical reference points in millimeters.

\begin{tabular}{|llllll|}
\hline & $\begin{array}{l}\text { SOF- Nasal } \\
\text { Midline }\end{array}$ & $\begin{array}{l}\text { SOF-Temporal } \\
\text { Crest }\end{array}$ & $\begin{array}{l}\text { SOF- } \\
\text { Supraorbital } \\
\text { Rim }\end{array}$ & $\begin{array}{l}\text { SOF } \\
\text { Angle } \\
\text { IOF } \\
\text { (in } \\
\text { Degree) }\end{array}$ & SOF width \\
\hline Average & 0.76 & 0.51 & 0.26 & 0.18 & 0.05 \\
\hline $\begin{array}{l}\text { Standard } \\
\text { Deviation }\end{array}$ & 4.2 & 4.69 & 1.8 & 6.4 & 0.9 \\
\hline $\begin{array}{l}\text { Standard } \\
\text { Error }\end{array}$ & 0.67 & 0.75 & 0.28 & 1.02 & 0.14 \\
\hline t-test & 1.12 & 0.68 & 0.89 & 0.17 & 0.37 \\
\hline
\end{tabular}

TABLE 3: The morphometric distance of IOF on right and left side of the skull from different anatomical reference point.

\begin{tabular}{|c|c|c|c|c|c|c|c|c|c|c|c|c|c|c|}
\hline \multirow[t]{2}{*}{ No } & \multicolumn{2}{|c|}{$\begin{array}{c}\text { Zygomatico- } \\
\text { maxillary } \\
\text { Suture }\end{array}$} & \multicolumn{2}{|c|}{$\begin{array}{l}\text { Maxillary } \\
\text { Midline }\end{array}$} & \multicolumn{2}{|c|}{$\begin{array}{c}\text { Infraorbital } \\
\text { Rim }\end{array}$} & \multicolumn{2}{|c|}{ Nasion } & \multicolumn{2}{|c|}{$\begin{array}{c}\text { Anterior } \\
\text { Nasal Spine }\end{array}$} & \multicolumn{2}{|c|}{$\begin{array}{c}\text { Maxillary } \\
\text { Alveolar } \\
\text { Crest }\end{array}$} & \multicolumn{2}{|c|}{$\begin{array}{l}\text { Width of the } \\
\text { foramen }\end{array}$} \\
\hline & Left & Right & Left & Right & Left & Right & Left & Right & Left & Right & Left & Right & Left & Right \\
\hline 1 & 0 & 1.4 & 40 & 41 & 4.2 & 5 & 45 & 45 & 38 & 35 & 27 & 27 & 4 & 5 \\
\hline 2 & 4 & 2.4 & 38 & 39 & 6 & 6 & 41 & 44 & 34 & 35 & 26 & 26 & 3.8 & 3.8 \\
\hline 3 & 3.1 & 4.5 & 44 & 45 & 6 & 7 & 44 & 45 & 34 & 33 & 28 & 28 & 5 & 4.5 \\
\hline 4 & 2.1 & 4.7 & 40 & 39 & 7 & 6 & 44 & 42 & 34 & 33 & 27 & 27 & 3 & 4 \\
\hline 5 & 0.5 & 3.5 & 43 & 44 & 8 & 7 & 44 & 46 & 35 & 36 & 27 & 27 & 3 & 3 \\
\hline 6 & 0.6 & 2.7 & 42 & 40 & 6 & 6 & 43 & 43 & 34 & 32 & 26 & 28 & 3 & 2.3 \\
\hline 7 & 0.7 & 1.6 & 46 & 44 & 8 & 7 & 42 & 45 & 39 & 38 & 28 & 28 & 4.1 & 5 \\
\hline 8 & 0 & 1.9 & 43 & 42 & 7 & 8 & 44 & 43 & 30 & 35 & 37 & 27 & 4 & 4.1 \\
\hline 9 & 0.9 & 1.8 & 38 & 39 & 6 & 7 & 42 & 43 & 32 & 34 & 26 & 26 & 4.3 & 3.3 \\
\hline 10 & 3.6 & 2.7 & 45 & 45 & 10 & 9 & 44 & 44 & 34 & 35 & 30 & 30 & 3.7 & 3.7 \\
\hline 11 & 1.1 & 3.8 & 41 & 42 & 9 & 7 & 43 & 42 & 36 & 35 & 26 & 26 & 3.8 & 3.8 \\
\hline 12 & 1.2 & 5.3 & 42 & 40 & 7 & 8 & 49 & 50 & 39 & 37 & 27 & 27 & 3.9 & 4.1 \\
\hline 13 & 2.3 & 4.3 & 44 & 43 & 6 & 6 & 48 & 48 & 38 & 37 & 28 & 28 & 4.3 & 4.1 \\
\hline 14 & 7 & 3.6 & 47 & 47 & 5 & 4 & 50 & 48 & 40 & 40 & 27 & 28 & 6.1 & 7 \\
\hline 15 & 5.5 & 2.1 & 42 & 40 & 6 & 7 & 48 & 50 & 35 & 36 & 28 & 28 & 4 & 2.8 \\
\hline 16 & 4.8 & 1.6 & 41 & 41 & 6 & 5 & 45 & 44 & 33 & 35 & 27 & 27 & 4 & 6 \\
\hline 17 & 3.9 & 1.4 & 37 & 38 & 6 & 6 & 43 & 44 & 31 & 31 & 28 & 28 & 4.1 & 4 \\
\hline 18 & 3.3 & 3.1 & 39 & 40 & 6 & 6 & 43 & 44 & 36 & 36 & 29 & 29 & 4.3 & 4.1 \\
\hline 19 & 2.9 & 0 & 42 & 43 & 9 & 8 & 46 & 46 & 36 & 34 & 28 & 28 & 6.1 & 4.3 \\
\hline 20 & 2 & 1.4 & 43 & 42 & 8 & 9 & 42 & 46 & 33 & 35 & 27 & 27 & 4.3 & 4.2 \\
\hline 21 & 2.1 & 1.6 & 42 & 42 & 4 & 4 & 42 & 46 & 35 & 32 & 28 & 28 & 2.9 & 2.9 \\
\hline 22 & 2.2 & 1.7 & 39 & 39 & 5 & 5 & 43 & 44 & 37 & 35 & 31 & 31 & 2.4 & 3.5 \\
\hline 23 & 2.3 & 1.2 & 39 & 37 & 6 & 6 & 44 & 43 & 34 & 35 & 30 & 30 & 4.2 & 4.2 \\
\hline 24 & 2.4 & 2.4 & 36 & 37 & 7 & 5 & 38 & 39 & 30 & 34 & 31 & 29 & 2.8 & 4 \\
\hline 25 & 2.9 & 2.8 & 41 & 42 & 8 & 7 & 45 & 43 & 35 & 35 & 27 & 28 & 3 & 4.3 \\
\hline 26 & 3.1 & 2.4 & 39 & 39 & 6 & 5 & 42 & 41 & 34 & 33 & 28 & 28 & 2.4 & 3 \\
\hline 27 & 5.3 & 3.4 & 44 & 45 & 7 & 6 & 47 & 45 & 37 & 36 & 29 & 27 & 4.8 & 4.7 \\
\hline 28 & 2.8 & 2.4 & 38 & 38 & 8 & 8 & 42 & 41 & 33 & 31 & 28 & 28 & 3.8 & 4.2 \\
\hline 29 & 2.9 & 2.8 & 38 & 39 & 10 & 8 & 48 & 49 & 32 & 35 & 29 & 28 & 5 & 5 \\
\hline 30 & 2.8 & 1.4 & 39 & 40 & 6 & 6 & 40 & 40 & 32 & 35 & 27 & 27 & 3.4 & 3.3 \\
\hline 31 & 3.6 & 1.7 & 42 & 42 & 7 & 6 & 46 & 42 & 37 & 35 & 28 & 28 & 4.2 & 3.5 \\
\hline 32 & 2.9 & 1.8 & 44 & 44 & 8 & 5 & 47 & 41 & 39 & 36 & 30 & 26 & 3.7 & 3.2 \\
\hline 33 & 3.4 & 1.9 & 39 & 41 & 10 & 7 & 43 & 42 & 36 & 33 & 29 & 26 & 3.5 & 2.9 \\
\hline 34 & 3.4 & 5.5 & 42 & 39 & 7 & 8 & 46 & 39 & 34 & 32 & 28 & 28 & 2.9 & 3.6 \\
\hline 35 & 2.5 & 7.5 & 41 & 38 & 9 & 9 & 44 & 40 & 35 & 34 & 28 & 27 & 3.5 & 3.2 \\
\hline 36 & 2.9 & 1.6 & 44 & 39 & 8 & 7 & 47 & 41 & 39 & 36 & 27 & 27 & 3.3 & 3.3 \\
\hline 37 & 4.7 & 5.8 & 43 & 39 & 6 & 8 & 46 & 45 & 38 & 36 & 26 & 29 & 3.1 & 3.8 \\
\hline 38 & 3.8 & 6.2 & 42 & 42 & 7 & 9 & 46 & 46 & 37 & 32 & 27 & 30 & 3.6 & 3.9 \\
\hline 39 & 7.5 & 2.5 & 40 & 43 & 8 & 6 & 45 & 46 & 36 & 36 & 31 & 28 & 4.1 & 3.6 \\
\hline 40 & 2.4 & 1.7 & 38 & 40 & 7 & 7 & 43 & 44 & 34 & 31 & 30 & 27 & 3.4 & 3.3 \\
\hline Mean & 2.88 & 2.8 & 41.2 & 40.97 & 7 & 6.65 & 44.4 & 43.8 & 35 & 34.6 & 28.2 & 27.8 & 3.79 & 3.91 \\
\hline
\end{tabular}


Table 4: The mean morphometric distance of Infrorbital Foramen (IOF) in dry skull from different anatomical reference point in millimeter.

\begin{tabular}{|ccccccc|}
\hline & $\begin{array}{c}\text { IOF- } \\
\text { Zygomaticomaxillary } \\
\text { Suture }\end{array}$ & $\begin{array}{c}\text { IOF- } \\
\text { Maxillary } \\
\text { Midline }\end{array}$ & $\begin{array}{c}\text { IOF- } \\
\text { Infraorbital } \\
\text { Rim }\end{array}$ & $\begin{array}{c}\text { IOF- } \\
\text { ANS } \\
\text { (Angle } \\
\text { in } \\
\text { Degree) }\end{array}$ & $\begin{array}{c}\text { IOF } \\
\text { width }\end{array}$ & $\begin{array}{c}\text { IOF- } \\
\text { Alveolar } \\
\text { Crest }\end{array}$ \\
\hline Average & 0.05 & 0.2 & 0.355 & 0.525 & 0.11 & 0.4 \\
\hline $\begin{array}{c}\text { Standard } \\
\text { Deviation }\end{array}$ & 2.43 & 1.69 & 1.2 & 2.29 & 0.73 & 0.76 \\
\hline $\begin{array}{c}\text { Standard } \\
\text { Error }\end{array}$ & 0.38 & 0.27 & 0.19 & 0.36 & 0.34 & 0.12 \\
\hline t- test & 0.14 & 0.73 & 1.84 & 1.42 & 1.5 & 1.27 \\
\hline
\end{tabular}

\section{Conclusion}

The findings in this study add information to the literature concerning SOF/N and IOF. It also reinforces the ethnic variation in the occurrence or positioning, for anesthetic, therapeutic, diagnostic or invasive surgical purpose.

\section{References}

[1] Cutright B, Quillopa N, Schubert W: An anthropometric analysis of the key foramina for maxillofacial surgery. J Oral Maxillofac Surg 61:354-357, 2003

[2] Karakas P, Bozkir MG, Oguz O: Morphometric measurements from various references points in the orbit of male Caucasians. Surg Radiol Anat 24:358-362, 2003.

[3] Apinhasmit W, Chompoopong S, Methathrathip D,Sansuk R, Phetphunphiphat W: Supraorbital notch/ foramen, infraorbital foramen and mental foramen in Thais: Anthropometric measurement and surgical relevance. J Med Assoc Thai 89:975-2, 2006.

[4] Zide BM, Swift R. How to block and tackle the face: Plas Reconstr. Surg 101:840-851, 1998.

[5] Lee UY, Nam SH, Han SH, Choi KN, Kim TJ: Morphological characteristics of the infraorbital foramen and infraorbital canal using three dimensional model. Surg. Radiol. Anat 28 (2:115-120, 2006.

[6] Agthong S, Huanmanop T, Chentanez V: Anatomical variations of the supraorbital, infraorbital and mental foramen related to gender and side. J Oral Maxillofac Surg 63:800-804, 2005.

[7] Apinhasmit W, Methathrathip D, Chompoopong S, Sangvichien: Mental foramen in Thais: An anatomical variation related to gender and side. Surg Radiol Anat 28:529-533, 2006.

[8] Webster RC, Gaunt JM, Hamdan US, Fuleihan NS, Giandello PR, Smith RC: Supraorbital and supratrochlear notches and foramina: Anatomical variations and surgical relevance. Laryngoscope 96: 311-315, 1986.

[9] Keskil S, Gozil R, Calguner E: Common surgical pitfalls skull. Surg Neural 59: 288, 2003.

[10] Chung MS, Kim HJ, Kang HS, Chung IH: Locational relationship of the supraorbital notch, infraorbital fora men and mental foramina in Koreans. Acta Anat 154:162-166, 1995

[11] Gupta T: Localization of important facial foramina encountered in maxillofacial surgery. Clin Anat 21:633-640, 2008.

[12] Saylam, Ozer MA, Ozer C. Anatomical variation of the frontal and supraorbital transcranial passage. J Craniofac Surg 14:10-12, 2003.

[13] Beer GM, Putz R, Mager K, Schumacher M, Keil W: Variation of the frontal exit of the supraorbital nerve: An anatomic study. Plas Reconstr Surg 102 (02):334-341, 1998.

[14] Aziz SR, Marchema JM, Puran A: Anatomic characteristics of the infraorbital foramen: A cadaver study. J oral Maxillofac Surg 58: 992-996, 2000.

[15] Murphy TM: Somatic Blockade of Head and Neck. In: Cousins, MJ Bridenbaugh, P.O. (eds.): Neural Blockade. (2nd Ed). Lippincott, Philadelphia. 1988, 537.

[16] Blanton PL, Jeske AH: The key to profound local anesthesia. J Am Dent Assoc 134(6): 753-760, 2003.

[17] Brando FH, Machado SMRC, Aquino PJE, Junior RGC: The foramen and infraorbital nerve relating to the surgery for external access to the maxillary sinus (Caldwell -Luc). Arch Otorhinolaryngology. Sao Paulo 12(3): 342-346, 2008. 